\title{
Personal Identity in Adulthood
}

\author{
Elena Konstantinovna Fominykh
}

Kazan Federal University, Republic of Tatarstan, 420008, Kazan, Kremlyovskaya St., 18

\section{Doi:10.5901/mjss.2015.v6n3s1p483}

\begin{abstract}
The article deals with such a complex psychological phenomenon, as a personal self-determination. Theoretical analysis of the three main approaches in the classical direction to establish the essence of personal self-determination. Defined picture of personal self-determination of an adult at different levels of education. Empirical studies indicate the socio-psychological determinants of personal self-formedness of an adult.
\end{abstract}

Keywords: personal self-determination, personal determinants, education, security mechanism of formation of personal selfdetermination.

\section{Introduction}

In the context of the social and economic, as well as political transformations the social significance of their psychological support increases. In this case, a special role is played by the psychological science and practice, which has recently become more important in the main activity fields of the society. Under the current conditions, the issues of the personal formation, development and improvement of an individual are particularly important. The issue of developing personal identity is reflected in the works devoted to the issues of the personal self-development, in particular, the implementation of the personal potential, the individual's independent selection of values, construction of the life strategies by him. The amount of the works devoted to the personal aspects of the phenomenon, has been now significantly declined. Referring to the literature sources shows, that the existing theoretical and empirical concepts of the personal identity issue in the domestic science primarily concern the adolescence and youth. However, personal identity also extends to the adulthood, the confirmation of this could be found in "the point of no return decade" and "the mid-life crisis" described by psychologists. Thus, in his adulthood a person faces the issue of personal identity again, the solution of which is embodied in setting the new life goals or restating the former ones, and in finding a new meaning of life, as compared with the adolescent and youth ones, by a person. Throughout all his life a person has to determine his attitude to the social realm, to make a variety of choices in accordance with his value preferences, therefore during his development he constantly arrives at the need for personal identity. One of his performance indexes is the establishment of the value and semantic field, which is significantly influenced by the factors, such as the education level and professional experience.

Thus, this study reflects the issue of covering the personal identity phenomenon, as well as identifying the personal determinants, which determine the patterns of developing the personal identity of an adult. The subject of the study is the personal determinants, which determine the patterns of developing the personal identity of an adult.

The objective of our study is the theoretical analysis of the psychological phenomenon of "personal identity" and the identification of the individual differences in the level of developing the personal identity of adults with different education levels. The Theoretical Task: is to organize the main approaches to the issue of personal identity in the psychological science. The Empirical Task: is to identify the features of the personal identity of an adult on different education levels.

\section{Theoretical and Methodological Essentials of the Study}

Personal identity is a complex scientific construct, which has philosophical, sociological, psychological and educational aspects. Therefore, there are various approaches to defining this concept. According to the objectives of our study, let's get down to the psychological approach itself, which should be considered from the perspective of the foreign and domestic psychological schools.

Depending on their belonging to any particular school, the foreign authors have given different views on the existence of personal identity; their opinions are based on different degree of the human freedom from the external or 
internal conditions.

The theories of the so-called "extreme determinism", according to which personal identity is not possible, include Freud's Z. psychoanalysis and Skinner's B. neobiheviorism. According to these approaches human behaviour is completely determined - by the unconscious in the first case, in the second one - by the support of the actual social environment.

E. Erikson's identity theory is deemed to be the theory of moderate determinism. Despite considering the unconscious as the personality basis, Erikson $\mathrm{E}$. does not deny the influence of the environment, which is mostly expressed at the first four stages of the psychological and sexual development, and which is reduced because of the consciousness development. An important contribution made by Erickson E. to the study of personal identity, is his development of the identity issue, which is "firmly learned and personally taken self-image in all richness of the personal attitudes to the outworld with the appropriate behaviour patterns" (Erickson,1968). According to Erickson E., the determinant mechanism of identity development is a sequent identifications of a child with an adult (Erickson, 2006). Achieving identity gives the feeling of continuity of the adult experience. In some cases, identity was considered as the equivalent to personal identity in the foreign literature. However, we believe, that personal identity is a broader concept, as it includes not only the search for and finding identity, but also setting goals, finding the meaning of life and making ones own life.

The authors, who admit the existence of determinism and at the same time consider a person to be active and able to personal identity, includes existentially oriented authors, such as Fromm E., Frankl V., May R. and the representatives of the cognitive, as well as social and cognitive schools - Kelly J. and Bandura A. respectively. Personal identity is expressed in settling the issue of the degree of ones own freedom, according to Fromm E., in taking a certain position in relation to the internal and external circumstances, according to Frankl V., in being aware of ones own opportunities within the destiny, according to May R., in the ability to choose from the available personal constructs, and create new, according to Kelly J., in the ability to influence oneself, making ones own destiny, according to Bandura A..

The psychologists, such as Adler A., Maslow A., and Rogers K., fought the absolute freedom of a person from the external or internal conditions. Adler A. believed, that there is a creative force, embodied in the person himself, because of which he is self-determined. The works by Maslow A. show, that personal identity is a determination of ones own personal features, preferences and its implementation on the basis of a choice. According to Rogers K., personal identity is facilitated by the actualization trend, because of which a person fulfil his potential and gets rid of the external control (Rogers, 1977).

In the domestic psychological science the classical and post-classical approaches to personal identity could be identified.

The classical approach is based on the principle of Rubinstein's S. L. determinism. In his works (Rubinstein, 1976), (Rubinstein, 1999), he pays much attention to the idea of the activity of the personal identity agent. Introducing the concept of "the agent of a life" and analysing the issue of determining the behaviour, Rubinstein considers the ratio of the external and internal dependence of the human activity. It is internal dependence, which causes the refraction of the external influences and is the basis for understanding personal identity, according to the athor. In this context, personal identity acts as self-determination, the activity of a person himself. As "a person does not only take a certain position in relation to the world, but he also determines his attitude, what is the conscious personal identity of an individual" (Rubinstein, 1999, pp: 243). Active personal identity, which is expressed in real actions, contributes to the establishment and development of the internal conditions, giving the possibility to further personal identity.

Abulkhanova-Slavskaya K. A., Leontiev A.N., Mudrik A.V. also consider personal identity in the context of conscious activity of a person, which is focused to himself and determines the strategy for his own behaviour in the different life situations. According to Abulkhanova-Slavskaya K. A., personal identity is the awareness of his position by a person, which is formed within the coordinate system of the relations. At the same time, she emphasizes, that "personal identity and public activity of an individual depend on the set of attitudes (to the collective agent, to ones own place in the team and to its other members, etc.)" (Abulkhanova-Slavskaya, 1991, pp: 138). Leontiev A.N. indicates the activity of the position itself in the process of the individual self-construction, which, in his view, is the nature of personal identity, the activity on self-construction - is the active position (10).

The concept of activity is also presented in understanding the process of personal identity by Buyakas T.M. The author emphasizes, that during the process of personal identity "the need for finding the support in the external environment is eliminated and, on the contrary, there is the ability to completely rely on oneself - to make ones own choice" (Buyakas, 2002, pp: 32). As a result, a person is "brought to the life," take the feeling of the contact boundary between himself and the outside world. Such overcoming and gaining independence, which forms personal identity, describes the internal activity of a person. This activity is carried out within some "integrity" and "completeness", reflecting 
the semantic field of the agent, "what starts being the voice of inner necessity to his ears" (Buyakas, 2002, pp: 32). In this case, the issue concerning the value and semantic content of the personal identity process occurs, which will be considered below.

Thus, we could conclude, that personal identity is the condition for establishing the attitude, positively perceived by a person. The active human activity results in the proactive attitude, as a system of the value and semantic concepts, directly affects the process and the result of his personal identity. Therefore, we consider activity as a complicated description of the human activity during personal identity. Actually, the existence of conscious attitude is only a part of the personal identity outcome, as a person could be unable to implement it during the activity.

The examining nature of activity is also emphasized by Krylova N.B., who suggests, that personal identity is kept current and provided by the "cultural practices" of a person, what is, in fact, his self-examination in different life situations. In this perspective, personal identity acts as a sequence of acts of exposing and stating the individual position in the problem situations, the process and the result of selecting the purposes and means of self-fulfilment by a person in the particular life circumstances; the basic mechanism of gaining and demonstrating inner freedom. According to Krylova N.B., the nature of personal identity process is perceiving the choice as the moral right and psychological competence in "consciously directing the freedom of the will to a specific course of behaviour and activity, setting some goals and means of achieving them for oneself, identifying possible solutions of the problems based on the personal interest and position" (Krylova, 2000, pp: 52-58).

Taken this, we believe, that the reflexive analysis of the examining activity results allows a person to recognize successful and unsuccessful behaviour patterns and to develop an individual life strategy. Inner freedom of person, based on his will and responsibility, results in the conscious choice and understanding the consequences of his activity. This is due to the opposition of the principles of the free choice and determination of behaviour. If the principle of freedom leads a person to understanding the necessity of responsibility for their actions, then the principle of behaviour determination, on the contrary, relieves him of any responsibility, as it impose the only possible choice, allow taking the only possible decision.

According to the studies by Antsyferova L.I., Petrovsky V.A., the examining, problematic and conscious nature of activity is complemented by its creativity during personal identity. In this case, personal identity acts as the creative activity, focused on the person himself and his life. The construction and correction of his image by a person is a logical creative continuation of the self-knowledge process (Antsyferova 1992), (Petrovsky, 1992).

The orientation of personal identity to the human life results in that the demonstrated activity starts to become motivating in nature. In particular, the motivating nature of activity was emphasized by Bozhovich L.I. and Shendrik I. G., arguing, that personal identity as a personal choice of the further life regulates and systematized a variety of motivational choice trends, determing by both the direct interests and aptitudes of a person, and other diverse motives generated by the whole situation of choice (Bozhovich, 1995), (Shendrik, 1989). Emphasizing the importance of personal identity, Bozhovich L.I. does not give its unambiguous definition; it is "the selection of the future life, the need for finding ones place in the work, in the society, in the life," "the search for meaning and purpose of his existence," "the need for finding ones place in the general life flow". The most succinct definition of the need for personal identity is probably the one as the need for merging the generalized concepts of the world and oneself into a unified semantic system, and thereby defining the meaning of ones own existence. Shendrik I. G., considers personal identity as the process of establishing personal meanings, conscious motiv-formation and goal-setting, which keeps current the activity on self-assessment and the development of self-awareness. (Shendrik, 1989)

The activity aspect could be seen in the concept of Safin V.F. and Nikov G. P. on personal identity as the process of mastering the agent of the consciously settled goal, as well as the personally and socially important life fields respectively. In the psychological content, the covering the nature of personal identity, as it is accepted by the authors, could not be based on the subjective aspect of consciousness - the awareness of ones "self", which acts as an internal cause of the social maturation. They assume the description of the "self-determined person", who is a synonym of the "socially mature" person for the authors. Thus, Safin V.F. and Nikov G. P. considering self-identity as the formation of ideology, finding a balance between the understanding of the subjective qualities of ones "self" and the demands of society, rather use a sociological than a psychological approach. (Safin, 1986)

Generally, the value and semantic basis of personal identity is emphasized by many authors. Thus, according to Bodrov V.A., it is necessary to differentiate the effectiveness and procedural aspects of personal identity. As a result of leaning, consolidating and demonstrating the semantic personal entities, personal identity is reflected in the change and development of the personality. In case, personal identity is understood not only as a result, but as a process, it acts as an independent form of activity, focused on defining and establishing the life meaning orientations of a person (Bodrov, 2001). 
Leontiev D.A. suggests to understand personal identity as the individual refraction of the social norms and values, and, as a consequence, the selective attitude to the world, the choice of those activities, which a person assumes (Leontiev, 2000).

The similar concepts could be also seen in the studies by Gazman O.S. Personal identity is understood as "the process and the result of selection ones own positions, goals and means of self-fulfilment by a person in the particular life circumstances; the basic mechanism of gaining and demonstrating inner freedom by a person" (Gazman, 1995, pp: 81).

The view of this group of researchers is aligned with the opinion of Shibayeva M. M. on personal identity as specifying and reasoning the value and semantic grounds for his own life by an individual, as well as his choice of methods and forms of its implementation (19).

Thus, during the personal identity process a person selects: values and meanings of his own activity, goals and alternatives of self-fulfilment, the opportunities inside and outside himself, the methods, means, forms, and the social roles of self-fulfilment.

According to Shendrik I. G., choice is seen as not only an activity, but also as a factor of establishing the educational space of the agent. The nature of choice - is the search for meaning, "personal meaning" (according to Leontiev A.N.). The logic is as follows: searching and specifying the alternatives, determining the spectrum of all real opportunities inside and outside oneself, their analysis from the perspective of personal growth, specifying the clearly expressed criteria (positions) for matching the internal and external worlds (Shendrik, 1989).

While analysing this approach, Shendrik I. G. notes, that the selection process in all cases is focused on defining its meaning for oneself. Consequently, the selection of the activity values, ones own position and the program of individual activity by a person could only be considered to be a responsible one, when it is carried out after establishing his personal evaluation system.

Rubinstein S.L. expressed his attitude to personal identity otherwise and more strictly (Rubinstein, 1999), giving its definition laconically: a free destiny choice by of a person. It combines the concept of choosing ones own position (the life concept), and the idea of freedom.

As the literature review shows, nowadays there are three main approaches to establishing the nature of personal identity in the context of the classical school.

In the first case, while studying personal identity, psychologists emphasize finding the "inward nature" by a person. In the context of personal identity these authors put first the self-knowledge of a person himself,, because of which he defines his own attitude to life and his place in it (Leontiev A.N., Abulkhanova-Slavskaya K.A., Frumin I. D., Davydov V.V., Antsyferova L.I., Petrovsky A.V., Shchedrovitsky P.G. et al.)

In the second case, psychologists describe the process of personal identity through making a choice. In turn, its subsequent implementation in activity is directly related to the process of establishing motives and goals, as well as solving the problem in the meaning, which is followed by the awareness of personal values (Bozhovich L.I., Shendrik I. G., Leontiev D.A., Mudrik A.V., Rubinstein S.L., Gazman O.S., Shibayeva M. M. et al.).

In the third case, personal identity is seen as the process, which implies "the search for meaning and purpose of ones existence", establishing the purpose and meaning of life by an individual, and which is carried out concerning the current social values, for specifying and reasoning the value and semantic grounds for his own life concept (Safin V.F., Nikov G. P. et al.) (Safin, 1986).

In our opinion, the most complete and unifying all these points of view is the concept of personal identity, which is proposed by Ginzburg M.R.. The author, according to the works by Berdyayev N.A., Frank S.L., Bakhtin M.M., Rubinstein S.L., takes the notion of the dual, spiritual and material nature of a person, who lives simultaneously in two areas - the value and semantic, as well as spatial and temporal ones, as a basis for considering the concept of personal identity. In this case, the spatial and temporal area reflects the "real action", which, in turn, is the means of implementing the values and meanings. Ginsburg completes the proposed scheme by also the time aspect, considering the three elements - the past, the present and the future, through the concept of "the life space of a person", which refers to "a set of the individual values and meanings, and the space of the real action - the actual and potential one, covering the past, the present and the future "(Ginzburg, 1994, pp: 46). It should be noted, that the past, according to the author, exists as the implementation of the experience, the present reflects the reality and involves self-development, and the future exists as a project, ensuring the semantic and temporal perspective. In the context of this approach, personal identity is considered as the "conceptual construction of the life space by a person, which includes both a set of individual life meanings and the real action space (the actual and potential ones)" (Ginzburg, 1994, pp: 47).

The process of initiation and execution of personal identity is as follows: personality takes meanings, which it internally requires during this period of life. As a result of solving "the problem in the meaning" the most general semantic entities - values are recognized. Meanings and values create a draft of the future and thereby control the future course of 
the person's life. On the way of acquiring values a person constantly faces the selection problem. Moreover, the index of personal identity is only that selection, upon which the preference is given to the higher-order value. The spatial and temporal aspect of personal identity involves self-fulfilment and planning, which allows a person to imagine his future and to organize it, breaking it into a sequence of some purposes.

Thus, in the classical sense the personal identity issue occurs at the interface of interaction between the person and society, and could be possible because of the primary division of all things into two realities - the "subjective" and "objective" ones.

According to the post-classical system approach all the concepts, which contain "self-", involve "something going from inside, something self-caused, from inside induced and controlled". Klochko V.E. and Galazhinsky E.V. suggest the way of overcoming the dichotomy of internal and external behaviour causes by examining its relations within the system, the centre of which is a person. According to them, during the interaction between the agent and the object a new reality occurs, in which the "external" determinism disappears, as it also becomes "internal" to the generated system. A person is a complex self-organizing psychological system, produces new entities of the complex "combined" nature, on which he relies during his self-motion, self-development.

From our point of view, the data obtained by different researchers, do not contradict, but rather complement each other, as they allow considering personal identity as a complex, dynamic process, which carries out during the whole person's lifetime and includes the three basic elements: the active and activity, value and semantic, temporal ones; in this case, the process of personal identity is closely related to the decision making processes.

To sum the authors' opinions, we believe, that personal identity is a process of the conscious creative choice and the subsequent establishment of the proactive attitude by a person, on the basis of which he develops and implements the possible alternative actions in the particular life situations. This process involves the constant establishment of the concepts of himself and his environment, the place and the role in the society, the possible behaviour strategies, which are relevant to the social and cultural values, by a person. Personal identity simultaneously acts both as the result of the prior interaction between a person and other actors in the society, and the starting point to new situations of this interaction according to the consciously developed strategy of the individual behaviour. The process of personal identity, which is initially focused on the person himself, the establishment of his individuality, is carried out in the context of the interaction with the society and, ultimately, is intended to harmonize his relations with it.

\section{Methods}

For the purpose of solving the empirical tasks in accordance with the selected theoretical essentials of studying such phenomenon, as personal identity, the psychological and diagnostic system, comprising the following methods, has been developed: the "Life Meaning Orientations" Test (LMO) by Leontiev D.A.; the Methods for Studying Self-Relations by Pantileyev S.P.; the "Scales of Psychological Well-Being" Questionnaire by Ryff C.) adapted by Shevelenkov T.D., Fesenko P. P.); the "Morphological Test of Life Values" Methods (MTLV) by Sopov V.F. and Karpushina L.V.; the "SelfManagement Ability" Methods (SMA) by Peysakhov N. M.; the "Emotional Intellect" Methods by Hall M.; the "Motivation for Success" Test by Ehlers T.; the "Failure Avoidance Motivation" Test by Ehlers T..

The number of the total study sample was 140 people. The age of the subjects varied from 30 to 45 years. All the subjects were divided into four groups: the adults with secondary vocational education; with higher education, training in graduate studies, with two higher educations respectively.

The obtained data of the empirical study were processed through the mathematical and statistical analysis. The reliability of differences in index expression was assessed through the Student's t-test. The structures formed by the indexes were identified through the correlation analysis; the differences between the obtained structures were evaluated through the divergence analysis.

\section{The Results of Empirical Study}

The comparative analysis of the mean values of indexes, which determine the patterns of personal identity, has shown, that personal identity in adulthood among the people with different education levels, differs rather significantly. Then, we will consider the specifics of these differences.

For the purpose of identifying the features of the correlation structures of the adult's personal identity the correlation analysis was conducted, which allowed obtaining the following results. Out of the studied indexes in the first sampling (people in adulthood, with secondary vocational education), 4 series were formed, which included 20 indexes. The systemic factors are the internal locus of control indexes and positive relationships with the others. 
The parameter of the environment control is associated with the decision making parameter and the parameter of identifying the emotions of other people at the significance level of $p=0.01$. This indicates, that the feeling of confidence and competence in managing the affairs allows passing from a mental plan to real actions, as well as helping to influence the emotional states of the others.

The parameter of identifying the emotions of other people is also associated with the achievement parameter at the significance level of $p=0.01$. In adulthood the people with secondary vocational education, believe, that the solution of some life problems directly depends on the ability to influence the emotional states of other people.

The empathy parameter is associated with the parameter of positive relationships with others and the correction parameter at the significance level of $p=0.01$. In other words, the ability to empathize the other person and the competence in supporting him allows reconsidering ones own position, reaching a compromise, thus, establishing pleasant and trusting relationships.

The empathy parameter is also negatively associated with the index of self-incrimination at the significance level of $p=0.001$ : the higher empathy is, the lower self-incrimination is.

The parameter of spiritual satisfaction is associated with the parameter of positive relationships with the others and the life purpose parameter at the significance level of $p=0.01$. This shows, that if managing the moral and ethical principles is a certain value for a person, it will help him both to achieve his objectives, and to establish positive relationships with the people around him.

The life purpose parameter is associated with the internal locus of control parameter and the self-development parameter at the significance level of $p=0.01$. A man with conscious and meaningful goals for the future believes, that he will be able to implement and achieve them in reality, while constantly working on the development of his features and abilities.

The internal locus of control parameter is also associated with the emotional awareness parameter and the parameter of achieving success motivation at the significance level of $p=0.01$. The relations are quite logical: the concept of him as a strong personality, who is able to build his life in accordance with his goals and objectives, contributes to achieving the success.

The parameter of achieving success motivation is associated with the planning parameter at the significance level of $p=0.01$. The commitment to achieve success makes a person to execute the mental work on forming a certain plan, which allows achieving this success. Out of the studied indexes in the second sampling (people in adulthood, with higher education) 2 series were formed, which included 27 indexes.

Out of the studied indexes in the fourth sampling (people in adulthood, with two higher educations) one holistic serie was formed, which included 23 indexes.

The systemic factors are the indexes of living process, life efficiency, self-acceptance, quality assessing criterion and empathy.

The living process parameter is associated with the parameters of self-acceptance, contradiction analysis, quality assessing criterion, managing ones own emotions, empathy at the significance level of $p=0.001$. Life is perceived as an interesting and intensive one by a person, if he possesses inner harmony, in other words, takes himself for what he is; is able to feel confident in any situation, independently identifies the indexes, which will be taken as the measure of his success; is emotionally flexible, empathies the others and supports them.

The living process parameter is also associated with the life purpose parameter at the significance level of $p=$ 0.01: the available goals for the future, which assign the specific meaning and temporal perspective to his life, allow perceiving its process as the interesting and intensive one.

The life efficiency parameter is related to the parameters of autonomy, quality assessing criterion, self-motivation, empathy at the significance level of $p=0.01$. The productivity of the closed chapter of life is determined by how the person could manage to control and evaluate himself, according to his own standards, instead of those imposed by the society; to manage his emotions and behaviour, as well as to be emphatic to the state of the people around him.

The life efficiency parameter is also negatively associated with the parameters of self-incrimination, failure avoidance motivation, as well as the parameters of self-acceptance and managing ones own emotions at the significance level of $p=0.001$. The relations are quite logical: satisfaction of self-fulfilment will be possible, if the person objectively defines the true causes of the occasional mistakes and failures, in other words, he does not "grab the biggest piece of the pie", what in future involves the need for acting so, that he could avoid failures in any situation, especially where the results of his activity are evaluated by the other people. The closed chapter of the life will be considered as the very productive and meaningful one by a person, if during this period he possessed the inner harmony (took himself for what he was) and managed to control his emotions.

The internal locus of control parameter is associated with the parameters of the contradiction analysis, goal-setting, 
quality assessing criterion and empathy at the significance level of $p=0.01$. The concept of himself as a strong personality, who has the free choice to build his live in accordance with his goals and objectives allows a person to feel confident in any situation without effort, to make and constantly keep in mind the desired and required image, to develop the indexes, according to which he will evaluate his success, and also allows being thoughtful and emphatic to the others.

The openness parameter is associated with the parameter of maintaining personality at the significance level of $p=$ 0.01: criticism and inner honesty allow a person to maintain his individuality.

The self-management parameter is associated with the parameters of personal growth and maintaining personality at the significance level of $p=0.01$ and $p=0.001$, respectively. The relations are quite logical: a person, who believes, that the balance of his fortune rests with him, is able to maximally realize his potential and to ensure the maintenance of his individuality.

The autonomy parameter is associated with the parameters of self-development and maintaining ones personality at the significance level of $p=0.01$. If learning his features, developing his abilities and being able to rely on his own opinion, views, beliefs are of particular importance and value for a person, he will be able to maintain his individuality.

The life purpose parameter is associated with the parameter of the contradiction analysis at the level of $p=0.01$ : the available goals for the future, which assign the specific meaning and temporal perspective to his life, allows a person feel more confident in any situation.

The parameter of self-acceptance is associated with the parameters of contradiction analysis, self-control and managing ones own emotion at the significance level of $p=0.01$, as well as the parameters of quality assessing criterion and empathy at the significance level of $p=0.001$. In other words, taking oneself for what he is allows the person to feel confident in any life situations, to set the indexes, according to which he will evaluate himself, to monitor the objective achievement and to arbitrary control his emotions.

The parameter of self-development is negatively associated with the parameter of the failure avoidance motivation at the significance level of $p=0.01$ : if a person has the evident need for acting so, that he could avoid failures in any situation, it will be quite difficult for him to realize their potential.

The empathy parameter is associated with the parameters of contradiction analysis and quality assessing criterion at the significance level of $p=0.001$ and $p=0.01$, respectively. The ability to feel confident in different life situations, to set the indexes, according to which he will evaluate himself and his life contributes to developing the ability to be thoughtful to others and the competence in supporting them.

The data obtained during the other two samplings (people with higher education and adults, who train in graduate studies), have taken the intermediate position between the aforesaid samplings.

\section{Discussion}

While analysing the obtained results, subject to the divergence analysis data, we could say, that these groups of subjects are rather harmonious. Their representatives have a clear vision of themselves, their life, goals and values, positive and negative aspects, taken place in the society. Most indexes are logically related, what indicates the balance in various life fields. More rich and intensive relation patterns could be seen in adults with two higher educations, the least intensive patterns could be seen in adults with secondary vocational education. If the first ones are set apart by developing the personal identity and the continuous process of its execution, the second ones face the problem of composing the holistic "self" of the diverse and contradictory external and internal subjective material.

Thus, the empirical study of personal identity in adulthood made it possible to establish the relationship between the personal identity of an adult and the level of his education. On the one hand, personal identity, its selection form the attitude to the education, on the other hand - the education makes the process of personal identity more dynamic. The mechanism of this influence to a large extent depends on the objectives given to the education: the traditional ones, when a person uses his personality as the means for achieving the functional, as well as subjective and objective education, and the person-centered ones, when a person, on the contrary, sets the education as a goal in itself.

\section{Conclusion}

The theoretical analysis of the studied psychological phenomenon has shown, that personal identity is a process of conscious creative choice and the subsequent establishment of the proactive attitude by a person, on the basis of which he develops and implements the possible alternative actions in the particular life situations.

One of the major factors, which determine developing the personal identity of an adult, is the education level.

The adults with secondary vocational education are quite pleased with their lives and believe, that very little 
depends on themselves and their efforts, and therefore they prefer "living for today" and "going with the flow". Their inherent conformity covers almost all the life spheres. The basis for developing a sense of self-worth and increased selfappreciation is the high level of material well-being and favourable relationships with significant others.

The adults with higher education define themselves as active creators of their lives, firmly knowing, what they want to achieve and how to do it. They successfully organize the run of events, control their course, but the initiative covers only the certain periods of the events run, not their objective / subjective effects. It might be said, that they have no "life line". The most important for them is to maintain their personality.

The adults, who train in graduate studies, recognize the permanent development and self-improvement as their main value, the dynamics and the qualitative change are above all. They have a clear concept of the individual life-style: the decision on how and what for spending their life, how to fulfil themselves in it, and therefore they thoroughly plan their life, dividing its time into separate stages and defining the maximally specific goals at each one.

Finally, the adults with two higher educations, define themselves as the people, who are open, emphatic, friendly both to themselves and to the others. They are set apart by their ability to appropriately evaluate the positive and negative aspects and qualities. They see their development as extending their education path and delving into their inward nature.

The diagnostic system developed and implemented in the training process allows identifying the development features and the level of developing personal identity, as well as making the targeted influence on the development of the main elements of this integral description on its basis, thus, ensuring the psychological support for the productive personal identity of an educational actor at all stages of his development.

This study is specifying and complementary in nature to the previously conducted study of such integral description of personality, as the psychological competence in personal identity. (Fominykh, 2009)

We consider the more detailed examination of other factors and conditions influencing the development of the personal identity of an adult, in particular, the gender diversity and professional experience as the possible opportunities for the further studies.

Acknowledgements. The author thanks Kasimova Anastasia Viktorovna for active assistance in conducting the study.

\section{References}

Abulkhanova-Slavskaya, K. L. (1991). Life Strategy. M.: Mysl Publishers.

Antsyferova, L.I. (1992). Changes in Personality: Some Results of the Study, Journal of Psychology, 5, 12-25.

Antsyferova, L.I.( 1980). Psychological Patterns of Developing Adult Personality, as Well as the Issue of Continuing Education, Journal of Psychology, 2, 52-60.

Bozhovich, L.I. (1995). The Issues of Personality Development. M.: Publishing House of the Institute of Practical Psychology, Voronezh: MODEK RPC.

Bodrov, V.A. (2001). Psychology of Professional Competence. University Handbook. M.: PER SE Publishing House.

Buyakas, T. M. (2002). The Issue and Applied Psychology of Personal Identity, The Issues of Psychology, 2, 28-40.

Gazman, O.S. (1995). Personal Identity. New Educational Values: Gazman's O.S. Thesaurus for Teachers and School Psychologists. M.: Innovator Publishers.

Ginzburg, M.R. (1994). Psychological Content of Personal Identity, The Issues of Psychology, 3, 43-52.

Krylova, N. B. (2000). Cultural Studies in Education. M.: Narodnoye Obrazovanie Publishing House.

Leontiev, A.N. (1977). Activity. Consciousness. Personality. M.: State Publishing House of Political Literature.

Leontiev, D.A. (1993). Outlining the Psychology of Personality. M.: Smysl Publishers.

Leontiev, D.A. (2000). Psychology of Freedom: on Posing the Problem of Personal Self-Determination, Journal of Psychology, 21 (1), 15-25.

Petrovsky, V.A. (1992). Psychology of Non-Adaptive Activity. Russian Open University. M.: Gorbunok LLP.

Rubinstein, S.L. (1976). The Issues of General Psychology. M.: Pedagogika Publishers.

Rubinstein, S.L. (1999). Fundamentals of General Psychology. St. Petersburg: Piter Publishers.

Rogers, C. R. (1977). Carl Rogers on personal power: Inner strength and its revolutionary impact. New York: Delacorte Press.

Safin, V.F. (1986). Psychology of Personal Identity: Handbook. Sverdlovsk Teachers Training Institute. Sverdlovsk.

Shendrik, I. G. (1989). The Psychological Features of Personal Identity during the Transition from Childhood to Adulthood. PhD Thesis in Psychology. M.

Fominykh, E.K. (2009). The Psychological and Akmeological Support for the Productive Personal Identity of an Educational Actor. Proceeding of the Kazan State University, 151 (5), 248 - 255.

Erikson, E. H. (1968). Identity: Youth and Crisis N.Y.

Erikson, E. (2006). Identity: Youth and Crisis [Text]: Hand book: Engl. Translation. 2nd Edition. M.: Flinta Publishing House. 